\title{
Case Report: Unprovoked venous thromboembolism in a
}

\section{young adult [version 1; peer review: 1 approved, 1 approved with reservations]}

\author{
Jeyhan Dhabhar1, Varshil Mehta(D1,2, Nimit Desai1, Sameer Dawoodi1, \\ Sojib Bin Zaman (iD) 3
}

${ }^{1}$ Department of Internal Medicine, MGM Medical College, Navi Mumbai, India

${ }^{2}$ Department of Internal Medicine, Dr. L. H. Hiranandani Hospital, Mumbai, India

${ }^{3}$ Maternal and Child Health Division, International Centre for Diarrhoeal Disease Research, Bangladesh (icddr, b), Dhaka, Bangladesh

\begin{tabular}{l}
\hline V1 First published: 14 Feb 2019, 8:182 \\
https://doi.org/10.12688/f1000research.18202.1 \\
Latest published: 25 Mar 2019, 8:182 \\
https://doi.org/10.12688/f1000research.18202.2 \\
\hline
\end{tabular}

\section{Abstract}

A 24-year-old male was presented to us with sudden onset of chest pain and dyspnea for the past one hour. There was no history of calf pain, trauma, surgery, prolonged immobilization, long-haul air travel, bleeding diathesis or any other co-morbidity. The patient denied any addiction history. The Electrocardiogram showed tachycardia with $\mathrm{S}_{1} \mathrm{Q}$ ${ }_{3} T_{3}$ pattern. The left arterio-venous Doppler study was suggestive of a thrombus in popliteal vein and sapheno-popliteal junction. The CTPulmonary Angiogram scan was suggestive of a massive pulmonary thromboembolism. The patient was thrombolysed with Intravenous Alteplase immediately and was put on tab Rivaroxaban for maintenance. He was later discharged after being stable. Unprovoked venous thromboembolism (VTE) is very rare and has the potential to lead to pulmonary embolism which could be disastrous, especially in young adults. We present such a case where unprovoked VTE was diagnosed and treated. This case suggests that high clinical suspicion is the key for the diagnosis of acute pulmonary embolism, especially in the absence of history suggestive of deep vein thrombosis.

\section{Keywords}

Pulmonary Embolism, Idiopathic, Thromboembolism

\section{Open Peer Review}

Approval Status

1 2

\section{version 2}

(revision)

25 Mar 2019

version 1

14 Feb 2019

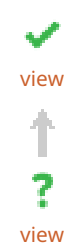

1. Shakti A. Goel ID, Indian Spinal Injuries

Center, New Delhi, India

2. Himel Mondal ID, Fakir Mohan Medical

College and Hospital, Balasore, India

Any reports and responses or comments on the article can be found at the end of the article. 
Corresponding authors: Varshil Mehta (varshilmehta@gmail.com), Sojib Bin Zaman (sojibbz@gmail.com)

Author roles: Dhabhar J: Conceptualization, Data Curation, Formal Analysis, Funding Acquisition, Investigation, Methodology, Project Administration, Resources, Software, Supervision, Validation, Visualization, Writing - Original Draft Preparation; Mehta V:

Conceptualization, Data Curation, Formal Analysis, Funding Acquisition, Investigation, Methodology, Project Administration, Resources, Software, Supervision, Writing - Original Draft Preparation, Writing - Review \& Editing; Desai N: Writing - Review \& Editing; Dawoodi S: Methodology, Resources, Writing - Review \& Editing; Zaman SB: Conceptualization, Project Administration, Supervision, Writing -

Original Draft Preparation, Writing - Review \& Editing

Competing interests: No competing interests were disclosed.

Grant information: The author(s) declared that no grants were involved in supporting this work.

Copyright: @ 2019 Dhabhar J et al. This is an open access article distributed under the terms of the Creative Commons Attribution License, which permits unrestricted use, distribution, and reproduction in any medium, provided the original work is properly cited.

How to cite this article: Dhabhar J, Mehta V, Desai $\mathrm{N}$ et al. Case Report: Unprovoked venous thromboembolism in a young adult [version 1; peer review: 1 approved, 1 approved with reservations] F1000Research 2019, 8:182

https://doi.org/10.12688/f1000research.18202.1

First published: 14 Feb 2019, 8:182 https://doi.org/10.12688/f1000research.18202.1 


\section{Introduction}

Venous thromboembolism (VTE) consists of pulmonary embolism (PE) and deep vein thrombosis (DVT). It is one of the leading causes of cardiovascular disability and impaired quality of life. It also causes major long-term complications, which include recurrent VTE, chronic thromboembolic pulmonary hypertension and post-thrombotic syndrome ${ }^{1}$.

PE is said to be the third leading cause for cardiovascular mortality (after myocardial infarction and stroke). It leads to 100000 deaths annually. It is not only the leading preventable cause of death in admitted patients ${ }^{1}$ but also the leading cause of deaths in mothers during pregnancy in developed countries ${ }^{2}$.

Idiopathic or unprovoked VTE is defined as "any VTE in the absence of an identifiable predisposing factor" ${ }^{3}$. Taking into consideration that unprovoked VTE is very rare, especially in the young adults, we put forward a case report of VTE in a 24-year-old man.

\section{Case report}

A 24-year-old man was brought to the emergency department of a hospital, by his office-colleagues, complaining of sudden onset of chest pain and dyspnea at rest, for the last one hour. It was not associated with sweating, palpitations, cough, hemoptysis, syncope, giddiness, leg pain, pedal edema, fever, rash, or any bleeding manifestations.

History of calf pain, trauma, surgery, prolonged immobilization, long-haul air travel, bleeding diathesis or any other co-morbidity was not reported by the patient. The patient also denied any addiction history. Family history was found to be insignificant.

On admission, the patient's heart rate was $114 / \mathrm{min}$, and blood pressure was $106 / 90 \mathrm{mmHg}$. His respiratory rate was $22 / \mathrm{min}$, and $\mathrm{O}_{2}$ saturation rate was $82 \%$ at room air. BMI was $20.76 \mathrm{~kg} / \mathrm{m}^{2}$. There was no murmur or gallop on cardiovascular examination. Air entry was reduced in the left infra-axillary region. Electrocardiogram (ECG) showed tachycardia with $\mathrm{S}_{1} \mathrm{Q}_{3} \mathrm{~T}_{3}$ pattern, and chest $\mathrm{X}$-ray was suggestive of obliteration of left costo-phrenic angle. The D-Dimer $(17.31 \mathrm{ug} / \mathrm{ml})$ was elevated, 34 times above the normal upper limit $(0.5 \mathrm{ug} / \mathrm{ml})$.

CT-Pulmonary Angiogram (Figure 1) was suggestive of a massive pulmonary thromboembolism. The pulmonary trunk was dilated to $\sim 30 \mathrm{~mm}$. There was a non-lumen occluding circumferential filling defect in the main pulmonary trunk, with maximum thickness of $4.5 \mathrm{~mm}$. A large partial-lumen occluding filling defect was noted in the left main pulmonary artery, which was extending further into the hilar branch, occluding the lumen completely. Another larger complete lumen occluding filling defect was noted in the right main pulmonary artery. These filling defects were extending into the segmental and subsegmental branches of the lateral segment of the right middle, lingual and bilateral lower lobe. The RV: LV ratio was 2:1. All four pulmonary veins were normal, and there was no evidence of mediastinal pathology.

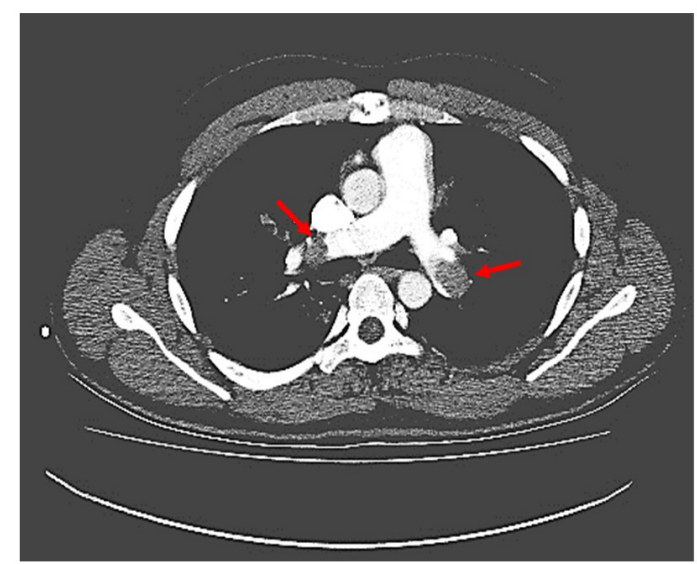

Figure 1. CT Pulmonary Angiogram showing non-lumen occluding thrombus (indicated by red arrows) in the right and left main pulmonary trunk.

On admission, the patient also underwent a bilateral arteriovenous Doppler study, which was suggestive of a partially-lumenoccluding thrombus in the proximal part of left popliteal vein and a completely lumen-occluding thrombus at the left saphenopopliteal junction, approximately $14 \mathrm{~cm}$ long. The veins of both legs showed arterialized waveforms.

On 2D echocardiography, right atrium and right ventricle was mildly dilated with grade I, tricuspid regurgitation (TR) and pulmonary arterial systolic pressure by TR jet was $55 \mathrm{mmHg}$ suggestive of moderate pulmonary artery hypertension. No regional wall motion abnormality was observed and left ventricular ejection fraction was $60 \%$.

The coagulation profile was within normal limits. All other blood investigations i.e. hemogram, serum electrolytes, renal and liver function tests were within normal range. The patient had mild hyperuricemia with serum uric acid level being $7.4 \mathrm{mg} / \mathrm{dL}$ (Normal - 3.5 - $7.2 \mathrm{mg} / \mathrm{dL}$ ). Cardiac enzymes (Creatine PhosphoKinase-MB and Troponin T) were mildly elevated.

Although it was a clear case of massive VTE, the underlying etiology of such an event could not be extrapolated. Since the patient was a 24-year-old man, without any risk factors or comorbidities, the final diagnosis of unprovoked VTE was made.

The patient was thrombolysed with Injection Alteplase infusion (100mg IV, over two hours) with Injection Enoxaparin $60 \mathrm{mg}$ given subcutaneously every 12 hours. After which, the patient developed hypotension which was treated with inotropic support. Although he had tachycardia post-thrombolysis for the next two days, his blood pressure returned to normal on the third day. 48-hours after giving thrombolytic treatment, the left lower limb venous doppler was done which was suggestive of a partial-lumen occluding the thrombus in popliteal vein extending from saphenopopliteal junction to mid-leg approximately $10 \mathrm{~cm}$ long. The CT-pulmonary angiogram was not repeated 
(post-thrombolysis), due to financial constraints; however, the patient improved drastically. He was shifted to general ward on day 4 post admission. Tab Rivaroxaban $15 \mathrm{mg}$ (12 hourly, orally) was prescribed for the next three weeks. The patient was discharged successfully on the $15^{\text {th }}$ day of admission. One week after discharge, the patient was advised Tab. Rivaroxaban $20 \mathrm{mg}$, once daily.

\section{Discussion}

VTE in a young male patient is life-threatening, especially if it is unprovoked. The most common and important ECG finding in a patient with PE is sinus tachycardia and the presence of $\mathrm{S}_{1} \mathrm{Q}_{3} \mathrm{~T}_{3}$ pattern in the ECG. Presence of these findings shortened the time for diagnosis of acute $\mathrm{PE}$ in our patient and the management after that ${ }^{4}$.

Literature suggests that the risk of early death among patients with symptomatic PE is 18-fold higher when compared with the patients having DVT alone ${ }^{5}$. Had this patient presented with sinus tachycardia alone, he would have undergone a battery of investigations, and prompt thrombolysis would have been delayed. Furthermore, the incidence rate of VTE is about 1.5 per 1,000 person-years while appearance of DVT is twice as common ${ }^{6}$.

Since our patient did not have any clinical features suggestive of DVT, having a Doppler study suggestive of DVT, was more of an additional finding, confirming VTE in this patient. A young man with sudden chest pain and dyspnea without any leg pain and who is otherwise healthy, is likely to be mismanaged, as suspicion of pulmonary or venous thrombo-embolism is quite low.

Before attempting to use the Wells criteria, a point-score based on clinical features and the likelihood of diagnoses other than $\mathrm{PE}$, the clinician must first have a suspicion of the diagnosis before attempting to apply the Wells criteria ${ }^{7}$. On admission, the Wells score for PE was 4.5 with a moderate probability of having a PE for the present patient based on the history and clinical features. The findings on CT Pulmonary Angiogram scan and ECG, increased the possibility of a PE, hence 3 points and 1.5 points were added for presence of tachycardia in our patient's total score. The well's score for DVT was 0 , as there was no history of cancer, surgery, immobilization, calf swelling, superficial veins, lower limb swelling, tenderness, paralysis or previous history of DVT. Hence high clinical suspicion remains the key in diagnosing PE, especially in the absence of DVT.

A case of unprovoked VTE, especially acute PE, needs to be extensively worked up, to prevent recurrence. Apart from history, family members need to be screened for coagulopathy or asymptomatic VTE, which was not done in this case. Although, coagulation profile, i.e. International Normalised Ratio (INR), prothrombin time, and activated partial thromboplastin time (APTT), was normal in our patient, it is advisable to do a thrombophilia profile. The thrombophilia profile will help to anticipate the tendency to develop pathological clotting or thrombotic disorders and consists of namely, factor $\mathrm{V}$ Leiden mutation, prothrombin gene mutation, protein $\mathrm{C}$ resistance, anti-beta 2 glycoprotein, anticardiolipin antibodies, protein $\mathrm{S}$ activity and serum homocysteine levels ${ }^{8}$. Due to the huge cost of these investigations, it becomes difficult to run such investigations while dealing with a case of acute PE in hospital. Thrombophilia profile is not indicated for the patients who are on anticoagulation therapy. Our patient gave a negative consent for doing a thrombophilia profile, hence the procedure was not done.

Inj. Alteplase is indicated as a fibrinolytic agent for the lysis of the clot seen in acute massive $\mathrm{PE}^{9}$. Massive PE is caused by obstruction (more than $50 \%$ of the cross-sectional area) of the pulmonary arterial tree, leading to an acute and subsequently severe cardiopulmonary failure due to right ventricular overload $^{10}$.

\section{Conclusion}

Silent VTE can develop into PE which may be unrecognized for a long time before the clinical features develop. High clinical suspicion is the key, for the diagnosis of acute PE in young patients, especially in the absence of history suggestive of DVT. In the absence of hemodynamic instability, the decision of fibrinolysis, in acute massive PE, largely depends on CT-Pulmonary Angiogram.

\section{Consent}

Written informed consent was taken from the patient and hospital authority to publish this case.

\section{Data availability}

All data underlying the results are available as part of the article and no additional source data are required.

\section{Grant information}

The authors declare that no grants were involved in supporting this work.

Acknowledgments

Medkrux Research Group.
1. Jerjes-Sánchez C: Mechanisms of thrombosis. In: Thrombolysis in Pulmonary Embolism Springer, Berlin. 2015; 1-17. Publisher Full Text
2. Konstantinides SV, Barco S, Lankeit M, et al:: Management of Pulmonary Embolism: An Update. J Am Coll Cardiol. 2016; 67(2): 976-990. PubMed Abstract | Publisher Full Text 
3. Iorio A, Kearon C, Filippucci E, et al.: Risk of recurrence after a first episode of symptomatic venous thromboembolism provoked by a transient risk factor: a systematic review. Arch Intern Med. 2010; 170(19): 1710-6.

PubMed Abstract | Publisher Full Text

4. Tapson VF: Acute pulmonary embolism. N Engl J Med. 2008; 358(10): 1037-52. PubMed Abstract | Publisher Full Text

5. Heit JA, Silverstein MD, Mohr DN, et al.: Predictors of survival after deep vein thrombosis and pulmonary embolism: a population-based, cohort study. Arch Intern Med. 1999; 159(5): 445-453.

PubMed Abstract | Publisher Full Text

6. Naess IA, Christiansen SC, Romundstad P, et al:: Incidence and mortality of venous thrombosis: a population-based study. J Thromb Haemost. 2007; 5(4): 692-9. PubMed Abstract | Publisher Full Text

7. Wells PS, Anderson DR, Rodger M, et al.: Excluding pulmonary embolism at the bedside without diagnostic imaging: management of patients with suspected pulmonary embolism presenting to the emergency department by using a simple clinical model and d-dimer. Ann Intern Med. 2001; 135(2): 98-107. PubMed Abstract | Publisher Full Text

8. Venous thromboembolic diseases: diagnosis, management and thrombophilia testing. Clinical guideline [CG144]. Published on 27 June 2012, Last updated on November 2015.

Reference Source

9. Martin C, Sobolewski K, Bridgeman P, et al:: Systemic Thrombolysis for Pulmonary Embolism: A Review. P T. 2016; 41(12): 770-775. PubMed Abstract | Free Full Text

10. Sadeghi A, Brevetti GR, Kim S, et al:: Acute massive pulmonary embolism: role of the cardiac surgeon. Tex Heart Inst J. 2005; 32(3): 430-433. PubMed Abstract | Free Full Text 


\section{Open Peer Review}

\section{Current Peer Review Status:}

\section{Version 1}

Reviewer Report 18 March 2019

https://doi.org/10.5256/f1000research.19910.r45517

(C) 2019 Mondal H. This is an open access peer review report distributed under the terms of the Creative Commons Attribution License, which permits unrestricted use, distribution, and reproduction in any medium, provided the original work is properly cited.

\section{Himel Mondal}

Department of Physiology, Fakir Mohan Medical College and Hospital, Balasore, Odisha, India

\section{Overall evaluation}

This is an interesting case report of venous thromboembolism in a young adult male without any predisposing factors. The authors described the case in detail with relevant and recent literature references. However, there is a need of a minor revision to enrich the manuscript. The author may revise the manuscript keeping in following points in mind:

\section{Title}

As this is a case of a "young adult male," authors may add the word "male" in the title of the manuscript.

\section{Abstract}

The patient presented with chest pain and dyspnoea. The second line of the "Abstract" described that the patient did not have any "calf pain." Authors could add some cardiological history. They could also add a glimpse of clinical examination (especially heart rate and rhythm) rather than starting with "ECG showed tachycardia..."

\section{Keywords}

Authors may add more keywords according to MeSH for wider dissemination of the article.

\section{Introduction}

PE causes "100000 deaths" annually. Is it global or regional data? Please specify.

\section{Case report}

Authors may add the time when the patient was brought to the hospital, along with the nature of his works in previous 12 hours, if the information is available.

What was the rhythm of the pulse in clinical examination? If the data is available, the authors may add it.

\section{Discussion}


Discussion is adequate and well written.

\section{Conclusion}

Written well and it is within the scope of the article.

\section{References}

References are relevant and recent.

Is the background of the case's history and progression described in sufficient detail? Yes

Are enough details provided of any physical examination and diagnostic tests, treatment given and outcomes?

Partly

Is sufficient discussion included of the importance of the findings and their relevance to future understanding of disease processes, diagnosis or treatment?

Yes

Is the case presented with sufficient detail to be useful for other practitioners?

Yes

Competing Interests: No competing interests were disclosed.

Reviewer Expertise: Cardiovascular physiology, Exercise physiology, Public health, Medical education

I confirm that I have read this submission and believe that I have an appropriate level of expertise to confirm that it is of an acceptable scientific standard.

\section{Author Response 18 Mar 2019}

Sojib Bin Zaman, International Centre For Diarrhoeal Disease Research, Dhaka, Bangladesh

Thank you for your reviews and approving it.

Changes we made:

In title: We have added "male" in the title.

Abstract: We have also added heart rate and bp in the abstract. Introduction: It leads to 100000 deaths annually globally The heart rhythm was normal and hence we didn't add it.

Hopefully, we have made adequate changes. Once again thank you for reviewing for us. Sojib.

Competing Interests: None 
Reviewer Report 15 February 2019

https://doi.org/10.5256/f1000research.19910.r44458

(C) 2019 Goel S. This is an open access peer review report distributed under the terms of the Creative Commons Attribution License, which permits unrestricted use, distribution, and reproduction in any medium, provided the original work is properly cited.

\section{Shakti A. Goel}

Department of Spine Surgery, Indian Spinal Injuries Center, New Delhi, Delhi, India

This is an interesting case report which discusses a rare phenomenon of unprovoked venous thromboembolism and its management. I would congratulate the authors for their work. However, there are a few concerns:

Though the authors have mentioned that there was no history of long air travel, it will be helpful to know if the patient had any history of long car travel before the event precipitated. It has been noted that DVT is commonly encountered in patients who undergo long car travel. Such information, if added, shall make the physicians more aware.

Did the physicians/authors conduct any clinical examination to test DVT. Were Homan's or Mosses sign performed. If yes, what were the results. If not, it will be helpful to know the reason for not performing them. A little detail on clinical examination of the patient should also be added to the manuscript besides the symptoms and findings.

It will also be helpful to know the Trop I values, if they were assessed by the authors.

The authors have mentioned that patient was kept on Rivaroxaban. Were there any side effects that were encountered. It will also be helpful if the authors could mention about the follow-up period of the patient in the manuscript.

Was any assessment done in the post discharge period. Was there any change in vessel size? Any adaptive remodeling seen with the treatment using Rivaroxaban .

Was the patient satisfied with the treatment? Any satisfaction index which was assessed. Authors may add it if found to be appropriate. They could use the attached reference for the same.

\section{References}

1. Guo LW, Wang B, Goel SA, Little C, et al.: Halofuginone stimulates adaptive remodeling and preserves re-endothelialization in balloon-injured rat carotid arteries.Circ Cardiovasc Interv. 2014; 7 (4): 594-601 PubMed Abstract | Publisher Full Text

2. Srivastava N, Goel S: A study of patient satisfaction level in inpatient spine department of a tertiary care multi-speciality hospital. Journal of Medical Research and Innovation. 2018. Publisher Full Text

3. Goel SA, Guo LW, Liu B, Kent KC: Mechanisms of post-intervention arterial remodelling. Cardiovasc Res. 2012; 96 (3): 363-71 PubMed Abstract | Publisher Full Text 
Is the background of the case's history and progression described in sufficient detail? Yes

Are enough details provided of any physical examination and diagnostic tests, treatment given and outcomes?

Partly

Is sufficient discussion included of the importance of the findings and their relevance to future understanding of disease processes, diagnosis or treatment?

Yes

Is the case presented with sufficient detail to be useful for other practitioners?

Yes

Competing Interests: No competing interests were disclosed.

Reviewer Expertise: Medicine, Surgery, Orthopaedics, Spine, Innovation, Technoinnovations

I confirm that I have read this submission and believe that I have an appropriate level of expertise to confirm that it is of an acceptable scientific standard, however I have significant reservations, as outlined above.

Author Response 15 Feb 2019

Sojib Bin Zaman, International Centre For Diarrhoeal Disease Research, Dhaka, Bangladesh

Thank you Dr for reviewing our paper and taking your time out for the same.

Please find my replies to your queries.

There was no history of prolonged air or car travel. Also, the detailed examination was performed and was deemed unremarkable; hence was not mentioned here (including Homan's and Moses sign).

Trop I level test are not available in our center, hence was not done, However, we did Trop T and CPK MB, which were normal.

The patient had followed up in our center for the first three months, following which relocated to Uttar Pradesh, India (his hometown). He experienced no side effects of Rivaroxaban. At three months, post discharge, a lower limb doppler was repeated which showed more than $50 \%$ reduction in size of the obstructing thrombus as compared to the previous one done at admission. Post three months of discharge, the patient has not returned back yet and has been lost to follow up.

The patient was most satisfied with the treatment and the recovery he'd made, but this was not recorded in a form of any official questionnaire (but he had mentioned this verbally); hence not mentioned here.

Hopefully, these comments will satisfy the queries. If you have any more queries, please feel free to post and we shall be happy to reply them.

Competing Interests: No competing interests present. 


\section{Reviewer Response 19 Feb 2019}

Shakti A. Goel, Indian Spinal Injuries Center, New Delhi, India

I had an opportunity to go through the review/reply and believe that the authors have addressed the comments meticulously. The article can be accepted once these details have been added to the article.

This article will certainly be very helpful for the physicians around the globe especially in low to middle income countries.

Competing Interests: None

The benefits of publishing with F1000Research:

- Your article is published within days, with no editorial bias

- You can publish traditional articles, null/negative results, case reports, data notes and more

- The peer review process is transparent and collaborative

- Your article is indexed in PubMed after passing peer review

- Dedicated customer support at every stage

For pre-submission enquiries, contact research@f1000.com 